\title{
Mobile Band Width Saving Estimate Model Using FMC
}

\author{
${ }^{1} \mathrm{P} . \mathrm{K}$. Chopra, ${ }^{2} \mathrm{~S}$. Jain and ${ }^{3}$ Venugopal Dasraju \\ ${ }^{1}$ HoD-ECE, AKGEC, Ghaziabad, U.P., India \\ ${ }^{2} \mathrm{HoD}$-ECE, IGIT, New Delhi, India \\ ${ }^{3}$ Devas Multimedia, Bangalore, India
}

\begin{abstract}
The model has been designed to calculate mobile bandwidth saving using FMC Techniques. The model is based on the average time the subscribers spend at home/office, the number of fixed lines in a mobile cellular coverage area, the average traffic generated by each subscriber, etc. The number of mobile phone subscribers in India has already crossed 700 million by December 2010 and increasing at about 18-20 million subscribers per month. This phenomenal growth also has lead to poor quality of service with frequent call drop outs etc. due to heavy traffic congestion especially in urban areas. The problem is compounded further by the limited amount of spectrum available for mobile cellular networks. The adoption of emerging NGN techniques coupled with Fixed Mobile Convergence (FMC) could alleviate the problems to a large extent. The FMC concept for spectrum saving is based on the concept of utilization of an existing resource in the form of fixed telephone lines for diverting the traffic on mobile networks in scenarios where such diversion will not affect the user service requirements. The enabling technologies that can lead to FMC have also been identified from user's perspective. A mathematical model has been developed to estimate the amount of spectrum that can be saved through FMC. Parametric analysis has been carried out with respect to the parameters which influence the spectrum saving. The model has been applied on real life networks to demonstrate the percentage of spectrum that can be saved. The spectrum thus saved can be used for increasing the number of mobile users without any addition to the existing mobile network infrastructure.
\end{abstract}

Key words: NGN, FMC, spectrum, mobile switching centre, FTE, MTNL, MBSEM, India

\section{INTRODUCTION}

It is interesting to scan the National Telecom Scenario which has an interesting story. There were two phones for every 10,000 Indians in 1947. In 1997, 4 years after the government gave up its monoply over the sector there were two phones for every 100 individuals and at the end of last year there were two phones for every ten citizens of India.

In this context one can safely say that the phenomenal growth of telecom in the last decade has gained such dimensions and momentum that cannot be stopped and it would continue to move forward with sheer force of its inertia. The telephone subscriber base has crossed 700 million in December, 2010. The details of teledensity by August, 2010 is as follows:

- Total telephone subscriber base 706.37 million

- Wireless subscription 670.60 million

- Wireline subscription declines to 35.77 million

- 18.18 million new additions in wireless per month

- Overall tele-density reaches $59.63 \%$

- Broadb and subscription 10.08 million
The number of telephone subscribers in India increased to 706.37 million at the end of August 2010 from 688.38 Million in July-2010 thereby registering a growth rate of $2.61 \%$. With this, the overall tele-density in India reaches $59.63 \%$.

Wireless Segment (GSM, CDMA and FWP): Wireless subscriber base increased from 652.42 million in July-2010 to 670.6 million at the end of August-2010 registering a growth of $2.79 \%$. Wireless tele-density stands at $56.61 \%$.

With this phenomenal growth rate especially in mobile sector there is a big possibility that in the near future the quality of service is likely to deteriorate. A day will come when you will be holding a mobile set in your hand but no call will go through due to congestion/choking of network. Even in the present scenario in a situation when everyone wants to talk to everyone due to may be a natural calamity or to greet one another during festival seasons, the network gets choked with no call going through. Adoption of NGN techniques coupled with Fixed Mobile Convergence (FMC) and adoption of certain user friendly technologies could

Corresponding Author: P.K. Chopra, HoD-ECE, AKGEC, Ghaziabad, U.P., India 
alleviate the spectrum congestion to a large extent. One of the main features of the FMC concept is to use the resources of an existing and under-utilized infrastructure such as fixed line telephone network to divert the traffic from mobile network for optimal utilization of the resources. FMC concept was mooted for addressing the spectrum congestion problem in mobile networks. However, the analysis was more general in nature and oriented towards revenue sharing models. It did not attempt to quantify the amount of spectrum that can be saved. This study addresses the usage patterns of the subscribers, the reasons for the same and identifies the technologies which could facilitate change of the present patterns so that FMC techniques can be adopted advantageously for saving the spectrum. A mathematical model has been developed to estimate the amount of spectrum based on the average time the subscribers spend at home/office, the number of fixed lines in a mobile cellular coverage area, the parametric monographs for different values of the above parameters. Finally, the model has been applied to a few real life networks in and around N Delhi to estimate the percentage of spectrum that can be saved through adoption of FMC. This spectrum saving can be used to increase the number of subscribers in the mobile network without any additional cost on the infrastructure or to improve the quality of service or a combination thereof.

\section{SUBSCRIBER USAGE PATTERN}

Concurrent to the mobile telecom growth over the past decade, the usage patterns of subscribers has also changed significantly. Before the mobile network growth, the main communication system was the Plain Old Telephone System (POTS). The high call charges of the mobile network compared to those of the fixed land line networks also made user discriminative and resort to fixed line telephone when access to the same was available like at home or at office. With significant drop in call charges of the mobile networks, the subscriber has started opting for convenience of use rather than cost of the call. This has resulted in the unhealthy habit of people tending to use mobile sets instead of landline phones even when they are at home or in the office where landline connections are available. The reasons of this tendency are:

- The ready availability of a directory of names/contacts in the mobile handset and not available in all models of fixed telephone
- Avoidance of efforts required to get up and access the land line phone which is generally at a fixed location in a house

- Facility of short messaging service in the mobile phone

An average person in a normal day, spends more time at home and office than in mobile environment (on a nontravelling day). Therefore, if he can take his calls on his home landline telephone or on office landline telephone, it would considerably save usage of critical mobile spectrum (Marathe et al., 2008). In this regard a Mobile Bandwidth Saving Estimate Model (MBSEM) has been designed and explained in the subsequent paragraphs.

\section{FIXED MOBILE CONVERGENCE (FMC)}

Fixed Mobile Convergence (FMC) is the integration of wireline and wireless networks and services to provide a seamless communications service for voice and data, regardless of the underlying access technologies (Vrdoljak et al., 2000).

FMC represents the convergence of fixed and mobile networks and using a single terminal that is capable of moving seamlessly across different types of environments (e.g., home, work, road, mobile, etc). The common use of these networks and above all their services is fixed mobile convergence.

Smooth cooperation between the Public Switched Telephone Networks (PSTN) and the Public Land Mobile Networks (PLMN) is one of the issues in telecommunications. The common use of these networks and above all their services is also encompassed in FMC. FMC presents an opportunity for landline operators to diversify and grab cellular customers. Operators operating on both landline/broadband and wireless can leverage existing subscribers for either of the two services and get them subscribed to the other service thereby giving the subscribers both the efficiency of landline services as well as the wide variety of services possible in wireless.

While this is an attractive value proposition for any type of service provider, wireline players stand to be the main beneficiaries of FMC, since its core revenue streamvoice has been eroding in the face of extraordinary growth in mobile usage. FMC or Fixed Mobile Convergence essentially entails the convergence or confluence of fixed-line and mobile wireless technologies in such a way that service providers can seamlessly blend two or more of these technologies to deliver enhanced user experience over a unified framework (Kataria and Logothetis, 2005). 


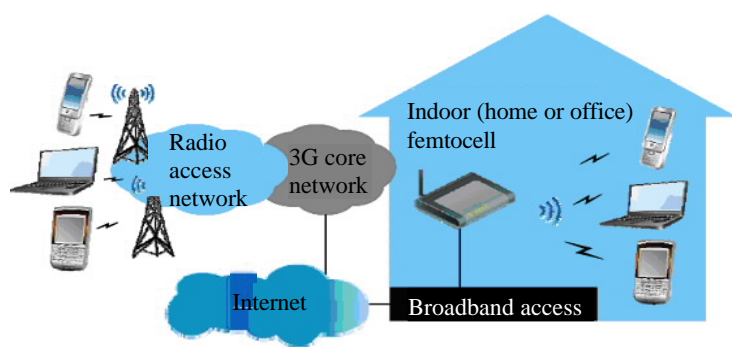

Fig. 1: The concept of femtocell for FMC

The following are some of the technologies which can be made use of to overcome the subscriber usage pattern so as to facilitate his usage of the fixed land line system while at home or office: use of femtocell access point in homes and offices where broadband fixed lines are available. Femtocell is an access point which is developed to work with a range of different cellular standards including CDMA, GSM and UMTS. Femtocell is a cellular access point (operate in licensed spectrum) used to connect to a mobile operator's network using home DSL or cable broadband connections (trail supports 2-5 mobile phones in a residential setting). They offer excellent mobile phone coverage at home for both voice and data but at the lower cost than outdoor service. The concept for femtocell for FMC is shown in Fig. 1 have blue tooth or Wi-Fi enabled fixed line telephone which can seamlessly route the calls to the person on his mobile handset; the telephone to have low bit data rate conversion module built-in to communicate to the exchange and then on to Mobile Switching Centre (MSC); the blue tooth or the Wi-Fi should be able to communicate with the home phone or office phone and automatic message should be sent to MSC and the MSC will establish communications with Fixed Telephone Exchange (FTE) to divert all calls to mobile from MSC to FTE. All mobile originated calls from FTE to either another fixed telephone or any mobile will be treated as if originating from fixed telephone.

\section{MOBILE BANDWIDTH SAVING ESTIMATE MODEL (MBSEM)}

The following model has been designed to calculate mobile bandwidth saving using FMC techniques. The model is based on the average time the subscribers spend at home/office, the number of fixed lines in a mobile cellular coverage area, the average traffic generated by each subscriber etc. (Marathe et al., 2008).

\section{Residential area cell analysis}

Number of mobile subscribers:

- Number of mobile subscribers in a residential area cell-Nmr
- Number of mobile subscribers having fixed home telephones in the residential area cell-Nhr

Assumption: Every house which has a fixed telephone will always have at least one mobile phone i.e., $\mathrm{Nmr}>=\mathrm{Nhr}$

Times spent at home and office:

- Average time in hours spent by a mobile subscriber at home in a day-Thr

- Average time in hours spent by a mobile subscriber in the residential area cell-Tmr

\section{Traffic estimates:}

- Average number of calls originated/received by a mobile subscriber while at home in an hour-Lhr

- Average no. of calls originated/received by a mobile subscriber in a residential area cell in an hour-Lmr (Lmr includes Lhr i.e., $\mathrm{Lmr}>=\mathrm{Lhr}$ )

- Number of hours over which the entire traffic originated/received is deemed to have occurred to estimate the calls during peak hour of traffic-Tpkr and average number of minutes per call duration-Tpc

Bandwidth saving: The bandwidth saving in a residential area cell due to FMC depends on the ratio of the average number of calls originated/received during peak hour of traffic by a mobile subscriber at home and the average number of calls originated/received during peak hour of traffic of the mobile subscriber in the residential area cell:

- The number of calls generated/received during peak hour traffic by a mobile subscriber at home-Lpkhr $=$ $(\mathrm{Lhr} \times \mathrm{Thr}) / \mathrm{Tpkr}$

- The number of calls generated/received during peak hour traffic by a mobile subscriber in the residential area cell-Lpkhr $=(\mathrm{Lhr} \times \mathrm{Thr}) / \mathrm{Tpkr}$

- The number of erlangs generated during peak hour traffic by a mobile subscriber at home-Epkhr $=\mathrm{Lpkhr} \times \mathrm{Tpc} / 60$

- The number of erlangs generated during peak hour traffic by a mobile subscriber in a residential area -Epkmr $=\mathrm{Lpkmr} \times \mathrm{Tpc} / 60$

- Ratio of the erlangs generated during peak hour by mobile subscribers at home and having fixed phones to the number of erlangs generated by mobile subscribers in the residential area cell-Erpkr $=$ $($ Epkhr/Epkmr $) \times(\mathrm{Nhr} / \mathrm{Nmr})$

- As the bandwidth is directly proportional to the Erlangs and simplifying the equation and rearranging the parameter, researchers have-ratio of the bandwidth (erlangs) required during peak hour traffic for supporting mobile subscribers at home and 
having fixed lines to the total bandwidth (erlangs) required during peak hours for supporting mobile subscribers in the residential area cell-BWrpkr $=$ $\mathrm{Erpkr}=(\mathrm{Lhr} / \mathrm{Lmr}) \times(\mathrm{Thr} / \mathrm{Tmr}) \times(\mathrm{Nhr} / \mathrm{Nmr})$

Under the assumption that all calls received by mobile subscribers at home in a residential area cell are diverted to home fixed phone while they are at home- $\%$ of total spectrum saved in a residential area cell through call diversion to fixed home telephone $=\mathrm{BWrpkr} \times 100=$ Erpkr $=(\mathrm{Lhr} / \mathrm{Lmr}) \times(\mathrm{Thr} / \mathrm{Tmr}) \times(\mathrm{Nhr} / \mathrm{Nmr}) \times 100$.

In the above analysis uniform average call duration Tpc for all categories of subscribers has been assumed. At a later stage, analysis can be done for different Tpc for $\mathrm{Nmr}$ and Nhr.

Business area cell analysis: Following a similar analysis as the residential area cell, the percentage of total spectrum saved in a business area cell through call diversion to fixed office telephone $=$ Bwrpko $\times 100=$ Erpko $=(\mathrm{Lob} / \mathrm{Lmb}) \times(\mathrm{Tob} / \mathrm{Tmb}) \times(\mathrm{Nob} / \mathrm{Nmb}) \times 100$ where

- Number of mobile subscribers in a business area cell$\mathrm{Nmb}$

- Number of mobile subscribers having fixed telephone at office in a business area cell-Nob

- Average time in hours spent by a mobile subscriber at office in a day-Tob

- Average time in hours spent by a mobile subscriber at office in a day-Tob

- Average number of calls originated/received by a mobile subscriber in a business area cell in an hourLmb

- Average number of calls originated/received by mobile subscriber while at office in an hour-Lob

- Ratio of the bandwidth (erlangs) required during peak hour traffic for supporting mobile subscribers at office and having fixed lines to the total bandwidth (erlangs) required during peak hours for supporting mobile subscribers in the business area cell BWrpko $=(\mathrm{Lhr} / \mathrm{Lmr}) \times(\mathrm{Thr} / \mathrm{Tmr}) \times(\mathrm{Nhr} / \mathrm{Nmr})$

Parametric analysis: The percentage spectrum saved in a residential area cell through:

$$
\begin{aligned}
\text { FMC }= & \text { BWrpkr } \times 100=\text { Erpkr }= \\
& (\mathrm{Lhr} / \mathrm{Lmr}) \times(\mathrm{Thr} / \mathrm{Tmr}) \times(\mathrm{Nhr} / \mathrm{Nmr}) \times 100
\end{aligned}
$$

The advantage of representing the spectrum saved as multiplication of ratios is that these are amenable for parametric analysis and can be carried out without the, need for absolute numbers like number of subscribers number of phones, number of hours and number of call minutes, etc.
The ratios also give a better visibility of the interplay between different parameters and the corresponding impact on spectrum saving. The following ratios and corresponding range of values have been chosen for the parametric study:

- Ratio of number of mobile subscribers having home fixed phones to the total number of mobile subscribers in a residential area $(\mathrm{Nhr}<=\mathrm{Nmr})$ $\mathrm{Nhr} / \mathrm{Nmr}(0-1)$

- Ratio of time spent by a mobile subscriber at home to the total time the mobile subscriber spends in the residential area in a day $(\mathrm{Thr}<=\mathrm{Tmr})$ - $(\mathrm{Thr} / \mathrm{Tmr})(0-1)$

- Ratio of the number of calls generated/received in an hour by a mobile subscribers at home having fixed telephone to the average number of calls generated/received in an hour by a mobile subscriber in a residential area in $1 \mathrm{~h}(\mathrm{Lhr}<=\mathrm{Lmr})-(\mathrm{Lhr} / \mathrm{Lmr})(0-1)$

- From the above we calculate the spectrum saved for different values of the ratios. Calculate BWrpkr

The graphic form of parametric analysis is shown in Fig. 2-4 and Table 1-3 for different values of the ratios chosen.

Most probable case: It will be worthwhile to study the bandwidth saving for a most probable case versus portion of calls which can be handled by FMC. The bandwidth saving percentage is expressed as:

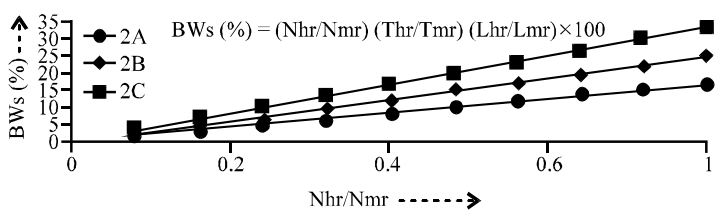

Fig. 2: Residential area-Bandwidth saving (Bws) $(\mathrm{Thr} / \mathrm{Tmr}=0.33)$

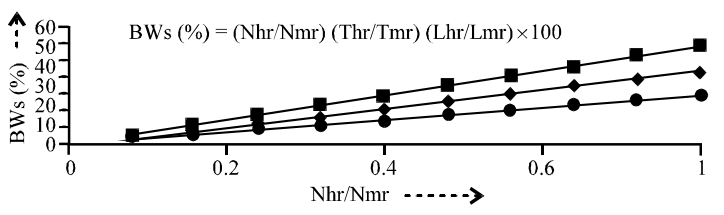

Fig. 3: Residential area-Bandwidth saving (Bws) $(\mathrm{Thr} / \mathrm{Tmr}=0.5)$

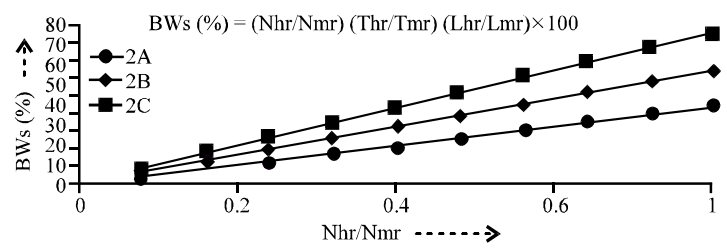

Fig. 4: Residential area-Bandwidth Saving (Bws) $(\mathrm{Thr} / \mathrm{Tmr}=0.75)$ 
Table 1: Parameters analysis for value $1 \mathrm{~A}, 1 \mathrm{~B}$ and $1 \mathrm{C}$

\begin{tabular}{|c|c|c|c|}
\hline \multirow{2}{*}{$\begin{array}{l}\mathrm{X} \text {-axis } \\
\text { (Nhr/Nmr) }\end{array}$} & \multicolumn{3}{|c|}{ Y-axis (Bws \%) } \\
\hline & $1 \mathrm{~A}$ & $1 \mathrm{~B}$ & $1 \mathrm{C}$ \\
\hline 0.1 & 1.65 & 2.48 & 3.3 \\
\hline 0.2 & 3.30 & 4.95 & 6.6 \\
\hline 0.3 & 4.95 & 7.43 & 9.9 \\
\hline 0.4 & 6.60 & 9.90 & 13.2 \\
\hline 0.5 & 8.25 & 12.38 & 16.5 \\
\hline 0.6 & 9.90 & 14.85 & 19.8 \\
\hline 0.7 & 11.55 & 17.33 & 23.1 \\
\hline 0.8 & 13.20 & 19.80 & 26.4 \\
\hline 0.9 & 14.85 & 22.28 & 29.7 \\
\hline 1.0 & 16.50 & 24.75 & 33.0 \\
\hline
\end{tabular}

$1 \mathrm{~A}: \mathrm{Bws} \%=0.5 \times 0.33 \times(\mathrm{Nhr} / \mathrm{Nmr}) \times 100(\mathrm{Lhr} / \mathrm{Lmr}=0.5, \mathrm{Thr} / \mathrm{Tmr}=0.33)$; 1B: $\mathrm{BWs} \%=0.75 \times 0.33 \times(\mathrm{Nhr} / \mathrm{Nmr}) \times 100(\mathrm{Lhr} / \mathrm{Lmr}=0.75, \mathrm{Thr} / \mathrm{Tmr}=$ $0.33) ; 1 \mathrm{C}: \mathrm{BWs} \%=1.0 \times 0.33 \times(\mathrm{Nhr} / \mathrm{Nmr}) \times 100(\mathrm{Lhr} / \mathrm{Lmr}=1.0, \mathrm{Thr} / \mathrm{Tmr}$ $=0.33) \mathrm{Thr} / \mathrm{Tmr}=0.3$; Nhr: Number of mobile subscribers having fixed home telephones in a residential cell; Nmr: Number of mobile subscribers in a residential cell; Thr: Average time in hours spent by a mobile subscriber at home in a day; Tmr: Average time in hours spent by a mobile subscriber in the residential area cell; Lhr: Average number of calls originated/received by a mobile subscriber while at home in an hour, Lmr: Average number of calls originated /received by a mobile subscriber In a residential area cell in an hour

Table 2: Parameters analysis of value $2 \mathrm{~A}, 2 \mathrm{~B}$ and $2 \mathrm{C}$

\begin{tabular}{llrr}
\hline & Y-axis (Bws \%) & & \\
\cline { 2 - 4 } (Nhr/Nmr) & \multicolumn{1}{c}{ 2A } & $2 \mathrm{~B}$ & $2 \mathrm{C}$ \\
\hline 0.1 & 2.50 & 3.75 & 5 \\
0.2 & 5.00 & 7.50 & 10 \\
0.3 & 7.50 & 11.25 & 15 \\
0.4 & 10.00 & 15.00 & 20 \\
0.5 & 12.50 & 18.75 & 25 \\
0.6 & 15.00 & 22.50 & 30 \\
0.7 & 17.50 & 26.25 & 35 \\
0.8 & 20.00 & 30.00 & 40 \\
0.9 & 22.50 & 33.75 & 45 \\
1.0 & 25.00 & 37.50 & 50 \\
\hline
\end{tabular}

$\mathrm{Thr} / \mathrm{Tmr}=0.75 \mathrm{BWs} \%=0.5 \times 0.5 \times(\mathrm{Nhr} / \mathrm{Nmr}) \times 100(\mathrm{Lhr} / \mathrm{Lmr}=0.5$, $\mathrm{Thr} / \mathrm{Tmr}=0.5) ; 2 \mathrm{~B}: \mathrm{BWs} \%=0.75 \times 0.5 \times(\mathrm{Nhr} / \mathrm{Nmr}) \times 100(\mathrm{Lhr} / \mathrm{Lmr}=0.75$, $\mathrm{Thr} / \mathrm{Tmr}=0.5) ; 2 \mathrm{C}: \mathrm{BWs} \%=1.0 \times 0.5 \times(\mathrm{Nhr} / \mathrm{Nmr}) \times 100(\mathrm{Lhr} / \mathrm{Lmr}=1.0$, $\mathrm{Thr} / \mathrm{Tmr}=0.5) \mathrm{Thr} / \mathrm{Tmr}=0.5$

Table 3: Parameters analysis of value $3 \mathrm{~A}, 3 \mathrm{~B}$ and $3 \mathrm{C}$

\begin{tabular}{|c|c|c|c|}
\hline \multirow{2}{*}{$\begin{array}{l}\mathrm{X} \text {-axis } \\
\text { (Nhr/Nmr) }\end{array}$} & \multicolumn{3}{|c|}{$\mathrm{Y}$-axis $(\mathrm{Bws} \%)$} \\
\hline & $3 \mathrm{~A}$ & $3 \mathrm{~B}$ & $3 \mathrm{C}$ \\
\hline 0.1 & 3.75 & 5.63 & 7.5 \\
\hline 0.2 & 7.50 & 11.25 & 15.0 \\
\hline 0.3 & 11.25 & 16.88 & 22.5 \\
\hline 0.4 & 15.00 & 22.50 & 30.0 \\
\hline 0.5 & 18.75 & 28.13 & 37.5 \\
\hline 0.6 & 22.50 & 33.75 & 45.0 \\
\hline 0.7 & 26.25 & 39.38 & 52.5 \\
\hline 0.8 & 30.00 & 45.00 & 60.0 \\
\hline 0.9 & 33.75 & 50.63 & 67.5 \\
\hline 1 & 37.50 & 56.25 & 75.0 \\
\hline
\end{tabular}

$3 \mathrm{~A}: \mathrm{BWs} \%=0.5 \times 0.75 \times(\mathrm{Nhr} / \mathrm{Nmr}) \times 100(\mathrm{Lhr} / \mathrm{Lmr}=0.5, \mathrm{Thr} / \mathrm{Tmr}=0.75)$; 3B: $\mathrm{BWs} \%=0.75 \times 0.75 \times(\mathrm{Nhr} / \mathrm{Nmr}) \times 100(\mathrm{Lhr} / \mathrm{Lmr}=0.75, \mathrm{Thr} / \mathrm{Tmr}=$ $0.75) ; 3 \mathrm{C}: \mathrm{BWs} \%=1.0 \times 0.75 \times(\mathrm{Nhr} / \mathrm{Nmr}) \times 100(\mathrm{Lhr} / \mathrm{Lmr}=1.0, \mathrm{Thr} / \mathrm{Tmr}$ $=0.75$ )

Table 4: Bandwidth saving for the probable case

\begin{tabular}{lc}
\hline Lhr/Lmr & BW saving (\%) \\
\hline 0.50 & 25 \\
0.75 & 35 \\
1.00 & 50 \\
\hline
\end{tabular}

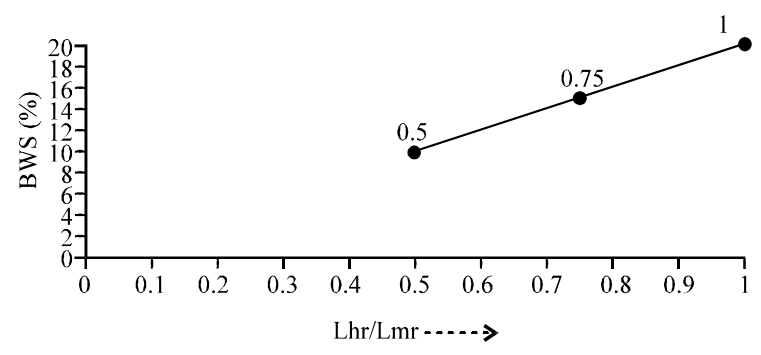

Fig. 5: Bandwidth saving (Bws \%)

BW saving $(\%)=(\mathrm{Lhr} / \mathrm{Lmr})(\mathrm{Nhr} / \mathrm{Nmr})(\mathrm{Thr} / \mathrm{Tmr}) \times 00$

It is expected that at least $60 \%$ of mobile customers will have a landline connection at home and a person devotes $10 \mathrm{~h}$ at home and $12 \mathrm{~h}$ in the residential area cell (Table 4). Accordingly:

$$
\mathrm{Nhr} / \mathrm{Nmr}=3 / 5 \text { and } \mathrm{Thr} / \mathrm{Tmr}=5 / 6
$$

BW saving $(\%)=(\mathrm{Lhr} / \mathrm{Lmr})(3 / 5)(5 / 6) \times 00$

or:

$$
\text { BW saving }(\%)=(\mathrm{Lhr} / \mathrm{Lmr}) \times 50
$$

The graph can serve as a ready reckoner to determine BW saving knowing the percentage of total calls which can be handled by FMC (Fig. 5).

\section{RESWENTIAL AREA CELL ANALYSIS}

For application of the MBSEM on bandwidth saving, the data of two residential areas of New Delhi, India (Dwarka and Puram) Fig. 6 and 7 have been considered. This data is taken from one of the service provider's viz. MTNL. The location of these two areas on the map is shown.

Survey of mobile users: A survey was carried out on approx 100 individuals to get details of usage of mobile phone by them. The survey was done keeping in mind those individuals who had landline connection available in their office and residence along with mobile phone. From the survey it is found out that on an average approx $50 \mathrm{~min}$ of mobile is being used by individuals while at home when landline phone is available. It is also seen that on an average $70 \mathrm{~min}$ of mobile is being used in office when landline phone is available. As presently we are doing study for residential areas, it means $50 \mathrm{~min}$ of spectrum used by individuals could have been spared for some other user had the call been diverted to the individual landline connection. 


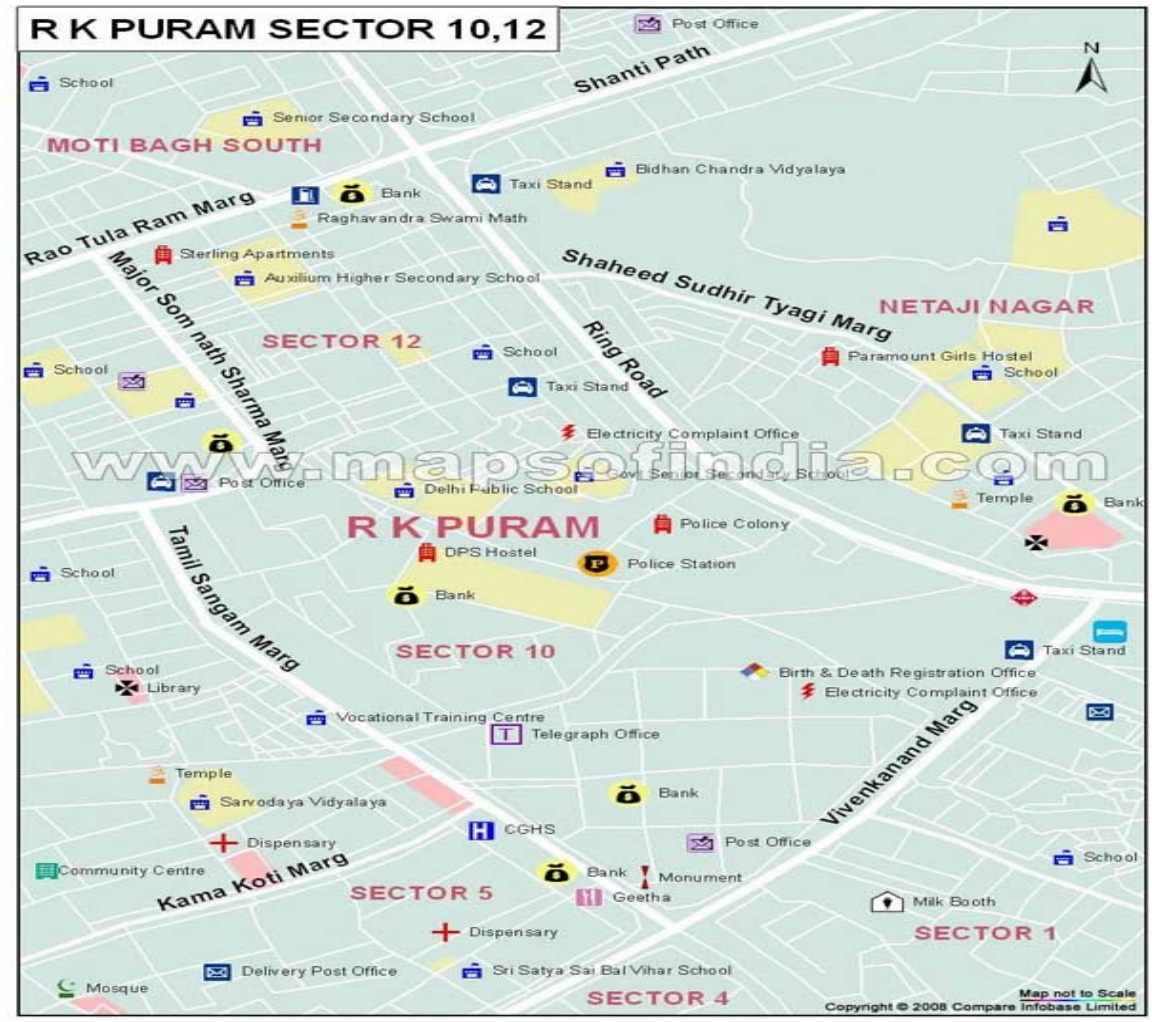

Fig. 6: R.K. Puram, N Delhi

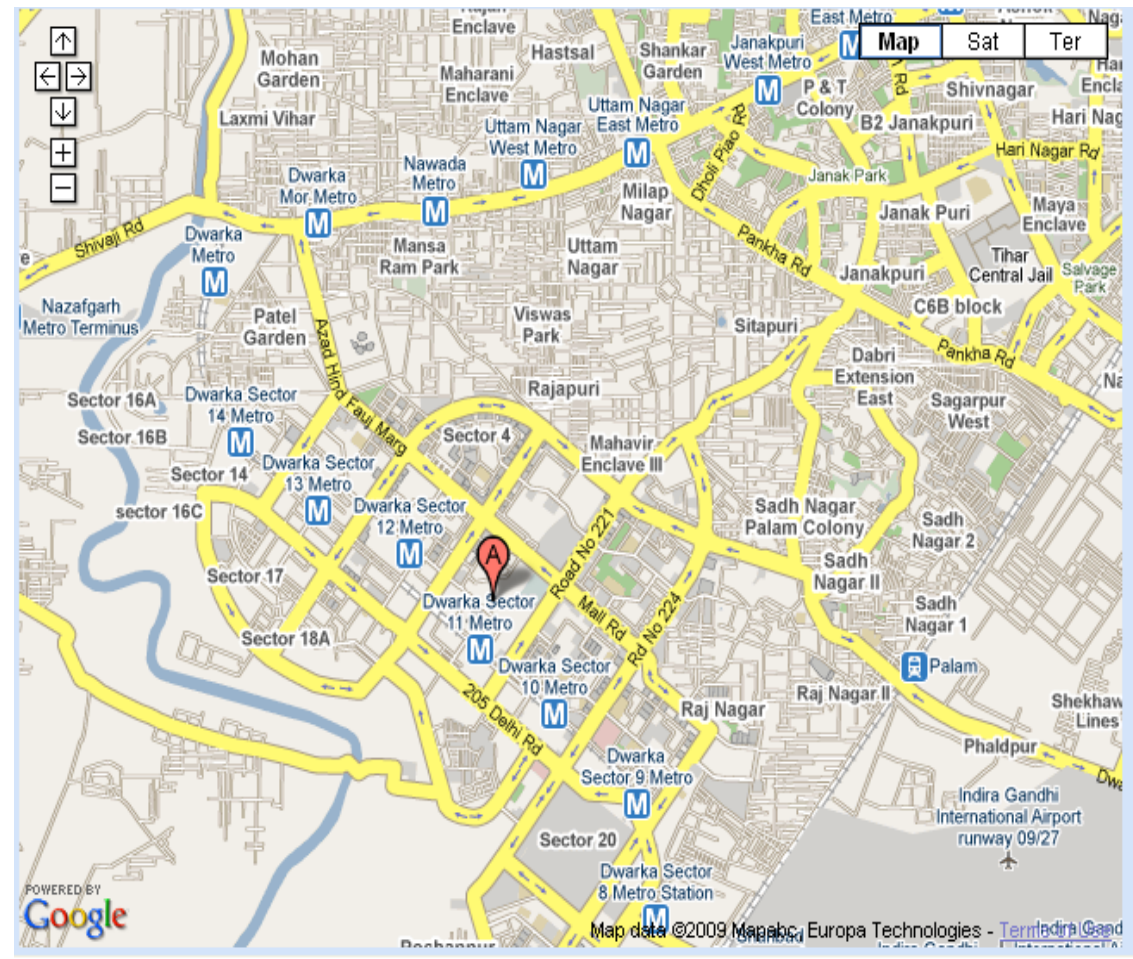

Fig. 7: Dwarka, N. Delhi 
Asian J. Inform. Technol., 10 (4): 154-164, 2011

\begin{tabular}{|c|c|c|c|c|c|}
\hline \multicolumn{2}{|c|}{ MTNL conection } & \multicolumn{3}{|c|}{ Mobile connections } & Landline connections \\
\hline \multicolumn{2}{|l|}{ Pre paid } & \multicolumn{3}{|c|}{7920} & 52365 \\
\hline \multicolumn{2}{|l|}{ Post paid } & \multicolumn{3}{|c|}{6542} & \multirow{2}{*}{$14462(\mathrm{Nmr})$} \\
\hline \multicolumn{2}{|l|}{ Total } & \multicolumn{3}{|r|}{-} & \\
\hline \multicolumn{6}{|c|}{ Table 6: Dawarka cell site details } \\
\hline $\begin{array}{l}\text { Site } \\
\text { name }\end{array}$ & Sector & $\begin{array}{c}\text { Site } \\
\text { ID }\end{array}$ & $\begin{array}{l}\text { DRI } \\
(\mathrm{A} / \mathrm{B} / \\
\mathrm{C} / \mathrm{D})\end{array}$ & $\begin{array}{l}\text { Peak hour traffic } \\
(\mathrm{A} / \mathrm{B} / \mathrm{C} / \mathrm{D}) \\
(\text { Erlangs) }\end{array}$ & $\begin{array}{l}\text { Total time slots or } \\
\text { maximum number of } \\
\text { simultaneous calls }\end{array}$ \\
\hline Dwarka & Sec 6-A & 509 & $4-4-4$ & $16.24 / 12.78 / 9.05$ & $\begin{array}{l}(7 \times 4)+(7 \times 4)+ \\
(7 \times 4)=84\end{array}$ \\
\hline Dwarka & Sec13-A & 522 & $8-8-8$ & $19.46 / 8.51 / 24.35$ & 168 \\
\hline Dwarka & Sec $10-A$ & 523 & $4-8-6$ & $11.93 / 21.6 / 11.04$ & 126 \\
\hline Dwarka & Sec 8-A & 528 & $4-6-4$ & $27.31 / 18.33 / 12.34$ & 98 \\
\hline Dwarka & Sec $19-A$ & 537 & $6-6-6$ & $9.8 / 7.29 / 12.11$ & 126 \\
\hline Dwarka & Sec 6 Mkt-A & 545 & $6-6-6$ & $12.48 / 15.81 / 12.33$ & 126 \\
\hline Dwarka & $\operatorname{Sec} 5-A$ & 552 & $6-4-8-2$ & $11.2 / 7.87 / 22.06 / 8.44$ & 140 \\
\hline Dwarka & Sec 23-A & 553 & $6-4-4-4$ & $11.47 / 3.42 / 1.21 / 5.89$ & 126 \\
\hline Dwarka & Sec $16-C-A$ & 1500 & $6-6-6$ & $10.59 / 3.66 / 2.68$ & 126 \\
\hline Dwarka & Sec 19-A & 1501 & $6-6-6$ & $10.32 / 5.03 / 15.65$ & 126 \\
\hline Dwarka & Sec $20 \mathrm{D}-\mathrm{A}$ & 1519 & $6-6-8$ & $6.44 / 15.07 / 13.53$ & 140 \\
\hline Dwarka & Sec 13-A & 1606 & $6-6-6$ & $11.49 / 4.43 / 9.12$ & 126 \\
\hline
\end{tabular}

Total number of BTS $=12$; Total time slots $=1512$

Residential area cell analysis-Dwarka, New Delhi: The details of data collected from MTNL-Delhi for residential area DWARKA is analysed as shown in Table 5. The MTNL connection details in Dwarka are as shown in Table 5. In Dwarka as on date MTNL mobile connection are less than landline connection.

MTNL has 12 base stations in Dwarka for providing mobile communications. Each base station operates either in three sector or four sector configuration (Sectors A, B and $\mathrm{C}$ or $\mathrm{A}, \mathrm{B}, \mathrm{C}$ and $\mathrm{D}$ ). The number of $\mathrm{RF}$ frequencies assigned for each sector in each base station differs based on the traffic. The details of number of carriers per BTS sector wise in Dwarka are shown in Table 6. A sector with 444 is as explained (Fig. 8):

- 444 for mobile talk RF frequency of $200 \mathrm{kHz}$ is required (BW required for mobile customers to talk)

- Each RF frequency has 8 time slots. One for signaling and 7 customers can talk simultaneously

- 444 means each sector 1,2 and 3 have four RF frequency each ( $8 \mathrm{RF}$ frequency is maximum that researchers can have):

In Sector $117 \times 4=28$ Customers can talk

In Sector $227 \times 4=28$ Customers can talk

In Sector $337 \times 4=28$ Customers can talk

Erlangs $=$ Number of calls in an hour $\times$

(Av. Duration of each call in minutes)/60

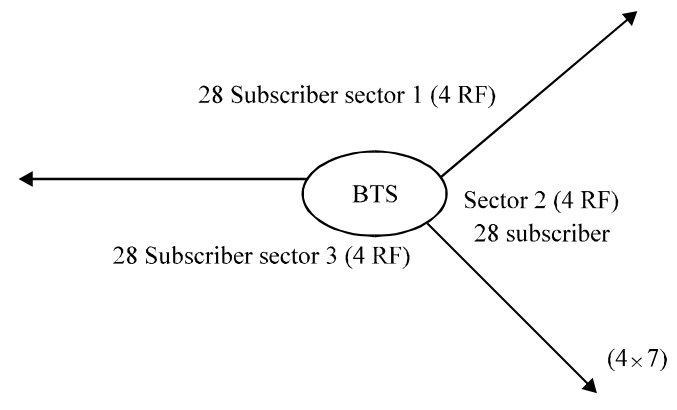

Fig. 8: Sector with 444

Site No. 1 i.e., Dwaraka Sec 6-A has three sectors each with 4 RF carriers. Site No. 7 i.e., Dwaraka ec 5-A has four sectors in a cell. The RF carriers in each sector are different with one sector assigned 6 carriers and other three 4,8 and 2 carriers, respectively. Each carrier is a paired carrier i.e., one RF frequency for the down link (base station to mobile) and one RF frequency for the uplink (mobile to base station).

Each carrier requires $200 \mathrm{kHz}$ bandwidth in the down link direction and $200 \mathrm{kHz}$ in the uplink direction. Each RF frequency has 8 time slots. One for signalling and 7 for traffic. In a sector where $4 \mathrm{RF}$ carriers are operating 28 $(4 \times 7)$ calls can happen simultaneously.

\section{Average traffic in the network:}

- Average number of calls for mobile connection per month is 270-MTNL

- Average number of calls for land line connections per month is $760-M T N L$

Estimating Nmr vis a vis the number of land line phones in a cell or a sector or per RF frequency: The present data available from Dwarka residential area does not give $\mathrm{Nmr}$ and $\mathrm{Nhr}$ on a cell basis. Researchers adopt an indirect method of estimating the $\mathrm{Nmr}$ and $\mathrm{Nhr}$ by calculating the average number of home land line phones and average number of mobile subscribers per RF frequency. The underlying assumption is that the distribution of home land line telephones in a cell area is pro rata the number of $\mathrm{RF}$ frequencies in a cell as the number of cells. This is a reasonable assumption to make as the $\mathrm{RF}$ frequencies per cell would have been based on some form of demographic distribution:

Number of base stations covering Dwarka $=2$

Total number RF frequencies $=12+24+18+14+18+18+$

$$
20+18+18+18+20+18=216
$$

Total number of land line phones $=52,365$ 
Average no. of land line phones per

$R F$ frequency $=52365 / 216=242$ approx

Number of mobile subscribers $=14462$

Average number of mobile subscribers

per RF frequency $=14462 / 216=67$ approx

From the above we can estimate the Nmr and fixed land lines per cell by multiplying the mobile subscribers and land lines per RF frequency with the number of RF frequencies in a cell. From the above analysis, number of land line telephones per RF frequency $>$ No of mobile subscribers per RF frequency. There is also assumed that all mobile subscribers have a land line in Dwarka.

Under above assumptions, $\mathrm{Nhr}=\mathrm{Nmr}$ and $\mathrm{Nhr} / \mathrm{Nmr}=1$

Estimation of the average time Thr and Tmr spent by a mobile subscriber at home and in the residential cell area: In the absence of any information on the above there is assumee with a reasonable basis based on usual working hours in urban India and their movement patterns in the residential area, a mobile subscriber spends about $10 \mathrm{~h}$ at home and about $2 \mathrm{~h}$ in the residential cell area; under the above assumption:

$$
\mathrm{Thr} / \mathrm{Tmr}=5 / 6=0.83
$$

Estimation of average number of calls received by a mobile subscriber: The values of $\mathrm{Lmr}$ and $\mathrm{Lhr}$ are not available directly in the data provided. They are bundled into average monthly numbers. Given, average number of calls for mobile connection per month $=270 /$ month.

This number represents when the mobile subscriber is at home within the cell area and also outside the cell area. Assumption that $40 \%$ of the number of mobile calls are made/received when the mobile subscriber is in the residential cell area $=108 /$ month. Further assumption that $70 \%$ of the number of mobile calls made/received in the area of the cell are when the mobile subscriber is at home $=76 /$ month .

Average number of phone calls made/received by the mobile subscriber per hour when he is in the area of the cell $\mathrm{Lmr}=108 /(30 \times 12)=0.3$. Average number of phone calls made/received by the mobile subscriber per hour when he is at home $\mathrm{Lhr}=76 /(30 \times 10)=0.253$. From the above analysis the ratio of $\mathrm{Lhr} / \mathrm{Lmr}=0.253 / 0.3=0.84$.

Percentage bandwidth saving: By plugging in the values of $\mathrm{Nhr} / \mathrm{Nmr}$, Thr/Tmr and Lhr/Lmr in the model. The percentage bandwidth saving by diverting the mobile calls to home land line $(\mathrm{FMC})=1 \times 0.83 \times 0.84 \times 100=69 \%$.
Validation of the traffic assumptions: Researchers try to validate the traffic assumptions made in earlier by analyzing the peak hour traffic data available and given in as discussed in this study. A sector which has between $50-60 \%$ loadings of the maximum supportable traffic has been chosen as the reference sector, e.g:

- Peak hour traffic in Dwaraka sec 6-A cell and sector A-16.24 Erlangs

- Peak hour to average hour traffic ratio-4

- Average hour traffic-4.06 Erlangs

- Number of RF carriers in the sector-4

- Average hour traffic per RF carrier-1.015 Erlangs

- Average call duration-3 min

- Number of calls per RF carrier $-(1.015 \times 60 / 3)=20.3$

- Average number of mobile subscriber per RF carrier -67

Average number of calls in an hour per mobile subscriber in a residential area cell-( $\mathrm{Lmr})=0.31$. This value is close to the value of Lhr.

Increase in subscriber capacity: The bandwidth saving derived can be used to add more subscribers without augmenting the existing equipment in the cell areas. Towards this we analyze the call statistics to arrive at the maximum number of subscribers that can be supported by the existing infrastructure. The call statistics are given as average number of calls per subscriber per month. From the previous sections estimated that:

- $\quad$ Average number of calls made/received by a mobile subscriber in the residential area per hour $\mathrm{Lmr}=0.3$

- Assumption-average duration of each call = $3 \mathrm{~min}$

- Average time a mobile subscriber in a residential area is on mobile phone in an hour $3 \times 0.3=0.9 \mathrm{~min}$

- $\quad$ Average number of erlangs of a mobile subscriber $=$ $0.9 / 60=0.015$ erlangs approx

- The ratio of peak hour to average hour traffic is used to size the maximum number of subscribers

- Assumption: ratio of peak hour to average hour traffic $=4$

- $\quad$ Peak erlangs of a mobile subscriber $(4 \times 0.015)=0.06$ erlangs

- $\quad$ Each RF carrier can support 7 simultaneous calls

- Number of erlangs each RF carrier support for a given grade of service $=5$ Erlangs

- Maximum number of mobile subscribers supported by an $\mathrm{RF}$ carrier $=5 / 0.06$

- Nmr_max $=83$

The present average number of subscriber per RF carriers is 67 which are quite close to the maximum number of subscribers that can be supported by the RF carrier. With the percentage savings in bandwidth as discussed 
Table 7: R K PURAM cell site details

\begin{tabular}{lccc}
\hline Site name & Site ID & DRI (A/B/C/D) & $\begin{array}{c}\text { Total time slots or maximum } \\
\text { number of simultaneous calls }\end{array}$ \\
RKPURAM-D2-P1/404-68-104 & 3171 & $6-6-6$ & $8.82 / 31.81 / 26.1$ \\
RKPURAM-D2-P1/404-68-104 & 3172 & $6-6-6$ & $5.73 / 17.26 / 22.36$ \\
RKPURAM-D2-P1/404-68-104 & 3173 & $8-8-8$ & $9.4 / 28.63 / 25.16$ \\
RKPURAM-D2-P3/404-68-104 & 3501 & $8-8-8$ & $15.04 / 15.19 / 13.92$ \\
RKPURAM-D2-P3/404-68-104 & 3502 & $8-8-8$ & $30.68 / 22.63 / 20.4$ \\
RKPURAM-D2-P3/404-68-104 & 3503 & $8-8-8$ & $6.92 / 5.98 / 5.74$ \\
RKPURAM-6-D2P3/404-68-104 & 3491 & $4-4-4$ & $15.36 / 13.75 / 11.44$ \\
RKPURAM-6-D2P3/404-68-104 & 3492 & $6-6-6$ & $34.72 / 20.96 / 20.43$ \\
RKPURAM-6-D2P3/404-68-104 & 3493 & $8-8-8$ & $46.28 / 40.35 / 36.5$ \\
RKPURAM-6-D2P3/404-68-104 & 3494 & $4-4-4$ & $0 / 14.87 / 13.41$ \\
\hline
\end{tabular}

Total Number of BTS $=10 ;$ total time slots $=1386$

before the maximum number of erlangs supportable by an $\mathrm{RF}$ carrier can go up by $69 \%$ and the correspondingly the number subscribers per RF carrier can go up by $69 \%$ i.e., from 83-140.

Residential area cell analysis-RK Puram, New Delhi: The details of MTNL sites for BTS site wise in RK Puram are shown in Table 7:

Erlangs $=($ Number of calls in an hour $) \times$

(Av. Duration of each call in minutes)/60

RK PURAM is a government residential colony in New Delhi. RK PURAM-D2-P1 has three sectors each with $6 \mathrm{RF}$ carriers. The RF carriers in each sector are different with two sectors assigned 4 carriers, three sectors assigned 6 carriers; five sectors assigned 8 carriers, respectively. Each carrier is a paired carrier i.e., one $\mathrm{RF}$ frequency for the down link (base station to mobile) and one RF frequency for the uplink (mobile to base station). Each carrier requires $200 \mathrm{kHz}$ band width in the down link direction and $200 \mathrm{kHz}$ in the uplink direction). Each RF frequency has 8 time slots, one for signaling and 7 for traffic. In a sector where $4 \mathrm{RF}$ carriers are operating $28(4 \times 7)$ calls can happen simultaneously.

\section{Number of telephone connections:}

- Number of mobile connections in a particular area in Rk Puram $=9490$

- Number of land line connections in the same area $=9800$

- Average number of calls per mobile connections per month $(\mathrm{GSM})=152$

- Average number of calls per landline connections per month $=760$

Estimating $\mathrm{Nmr}$ vis a vis the number of land line phones in a cell or a sector or per RF frequency: The present data available from $\mathrm{R} \mathrm{K}$ Puram does not give Nmr and $\mathrm{Nhr}$ on a cell basis. There is adopt the same methodology as has been applied to Dwarka residential area analysis:
- Number of base stations covering R K Puram $=10$

- $\quad$ Total number RF frequencies $=198(18+18+24+24+$ $24+24+12+18+24+12$ )

- $\quad$ Total number of land line phone $=9800$

- Average number of land line phones per RF frequency $=9800 / 198=49$ approx

- No of mobile subscribers $=9490$

- Average number of mobile subscribers per RF frequency $=9490 / 198=48$ approx

From the above there can estimate the $\mathrm{Nmr}$ and fixed land lines per cell by multiplying the mobile subscribers and land lines per RF frequency with the number of RF frequencies in a cell. From the above analysis, number of land line telephones per RF frequency $>$ No of mobile subscribers per RF frequency. There is also assumed that all mobile subscribers have a land line in $\mathrm{R} \mathrm{K}$ Puram. Under above assumptions, $\mathrm{Nhr}=\mathrm{Nmr}$ and $\mathrm{Nhr} / \mathrm{Nmr}=1$.

Estimation of the average time Thr and Tmr spent by a mobile subscriber at home and in the residential cell area: In the absence of any information on the above there is assume with a reasonable basis based on usual working hours in urban India and their movement patterns in the residential area, a mobile subscriber spends about $10 \mathrm{~h}$ at home and about $2 \mathrm{~h}$ in the residential cell area. Under the above assumption:

$$
\mathrm{Thr} / \mathrm{Tmr}=5 / 6=0.83
$$

Estimation of average number of calls received by a mobile subscriber: The values of Lmr and Lhr are not available directly in the data provided. They are bundled into average monthly numbers. Given, average number of calls for mobile connection per month $=152 /$ month .

This number represents when the mobile subscriber is at home within the cell area and also outside the cell area. Assumption that $40 \%$ of the number of mobile calls are made/received when the mobile subscriber is in the residential cell area $=61 /$ month. Further assumption that 
$70 \%$ of the number of mobile calls made/received in the area of the cell are when the mobile subscriber is at home $=48 /$ month. Average number of phone calls made/received by the mobile subscriber per hour when he is in the area of the cell-Lmr $=61 /(30 \times 12)=0.17$ average number of phone calls made/received by the mobile subscriber per hour when he is at home-Lhr $=43 /(30 \times 10)$ $=0.14$. From the above analysis the ratio of $\mathrm{Lhr} / \mathrm{Lmr}=$ $0.14 / 0.17=0.82$.

Percentage bandwidth saving: By plugging in the values of $\mathrm{Nhr} / \mathrm{Nmr}$, Thr/Tmr and $\mathrm{Lhr} / \mathrm{Lmr}$ in the model. The percentage bandwidth saving by diverting the mobile calls to home land line $(\mathrm{FMC})=1 \times 0.83 \times 0.82 \times 100=68.1 \%$.

Validation of the traffic assumptions: Researchers try to validate the traffic assumptions made as discussed earlier by analyzing the peak hour traffic data available as discussed earlier and adopting the similar approach as has been adopted for the Dwarka residential area, e.g:

- Peak hour traffic in RKPURAM-D2-P1/404-68-104 sector B-28.63 erlangs

- Peak hour to average hour traffic ratio-4

- Average hour traffic-7.16 erlangs

- Number of RF carriers in the sector-8

- Average hour traffic per RF carrier-0.89 erlangs

- Average call duration-3 min

- $\quad$ Number of calls per RF carrier- $(0.89 \times 30 / 3)=8.9$

- Average number of mobile subscriber per RF carrier (from section 6.3.3)-48

- Average number of calls in an hour per mobile subscriber in a residential area cell-Lmr 0.185

- This value is close to the value of Lhr arrived as discussed earlier

Increase in subscriber capacity: The bandwidth saving derived, it can be used to add more subscribers without augmenting the existing equipment in the cell areas. Towards this we analyze the call statistics to arrive at the maximum number of subscribers that can be supported by the existing infrastructure.

The call statistics are given as average number of calls per subscriber per month. From the previous sections there is estimated that: average number of calls made/received by a mobile subscriber in the residential area per hour-Lmr $=0.17$.

Assumption-average duration of each cal $1=3 \mathrm{~min}$ average time a mobile subscriber in a residential area is on mobile phone in an hour $=3 \times 0.17=0.51 \mathrm{~min}$. Average number of erlangs of a mobile subscriber $=0.51 / 60=0.009$ Erlangs approx. The ratio of peak hour to average hour traffic is used to size the maximum number of subscribers. Ratio of peak hour to average hour traffic $=4$ peak erlangs of a mobile subscriber $(4 \times 0.009)=0.036$ Erlangs. Each RF carrier can support 7 simultaneous calls $\mathrm{N}$ number of erlangs each RF carrier support for a given grade of service $=5$ Erlangs.

Maximum number of mobile subscribers supported by an $R F$ carrier $=5 / 0.036$. Nmr_max $=138.9$. The present average number of subscriber per RF carriers is 48 . With the percentage savings in bandwidth arrived as discussed before the maximum number of erlangs supportable by an $\mathrm{RF}$ carrier can go up by $68 \%$ and correspondingly the number subscribers per RF carrier can go up by $68 \%$ i.e., from 139-233.

Increases in subscriber capacity for Dwarka and R.K. Puram: The analysis indicate that if the same statistics hold using FMC the maximum number of subscribers per RF carrier can be increased by $69 \%$ ( for Dwarka) from 83-140 and for R K Puram with $68 \%$ saving from $139-233$ without adding additional $\mathrm{RF}$ carriers.

However, it may be noted that presently the average number of mobile subscribers per RF carrier in Dwarka is only 67 and in R K Puram 48 and it will take some time before the benefits of savings in bandwidth due to FMC is felt in these two areas.

\section{CONCLUSION}

Analysis bring out that savings in mobile spectrum in a cell area could be up to $69 \%$ under some assumptions by adopting FMC techniques. This savings can be traded off for increasing the number of subscribers up to $69 \%$ without any increase in the mobile infrastructure or for improvement in QoS or a combination thereof.

Getting the advantage of good voice quality of fixed landline telephone while talking on a mobile. With the number of mobile subscribers increasing rapidly worldwide, the mathematical model developed and explained in detail above will be a good tool for analyzing the bandwidth savings which could accrue due to FMC. The mobile service providers can take advantage of the same. To fully exploit the FMC techniques for spectrum saving, certain enabling technologies have to be in place. The trends indicate that such technologies will be in place as part of NGN-FMC and the service providers should work towards expediting the same.

\section{ACKNOWLEDGEMENT}

Researcher sincerely thanks University School of Engineering and Technology, Guru Govind 
Singh Indraprastha University, New Delhi for providing the opportunity and guidance for research work.

\section{REFERENCES}

Kataria, D. and D. Logothetis, 2005. Fixed mobile convergence: Network architecture, services, terminals and traffic management. Proceedings of the IEEE 16th International Symposium on Personal, Indoor and Mobile Radio Communications, Sept. 11-14, Berlin, pp: 2289-2300.
Marathe, N.V., U.B. Desai and S.N. Merchant, 2008. A new techno-business model for efficient utilization of wireless spectrum by online call forwarding leading towards fixed mobile convergence. Proceedings of the IET International Conference on Wireless, Mobile and Multimedia Networks, Jan. 11-12, Mumbai, pp: 92-94.

Vrdoljak, M., S.I. Vrdoljak and G. Skugor, 2000. Fixed-mobile convergence strategy: Technologies and market opportunities. IEEE Commun. Mag., 38: 116-121. 